\title{
DRAMATURGIA MITOPOETICĂ A LUI BLAGA ȘI RESCRIEREA CANONULUI REDEMPT,IUNII
}

\author{
Ioana Toloargă \\ ioana.toloarga@yahoo.com \\ Universitatea „Babeș-Bolyai,” Cluj-Napoca
}

\begin{abstract}
Taking in consideration a broad perspective on Romanian literature and the prevalence of the Byzantine religious model, the orthodox background that provides the dichotomie Good-Bad or Beautiful-Ugly as a statement, the present paper analyses Lucian Blaga's plays (Tulburarea apelor and Meșterul Manole) as an alternative model. The European cultural influences, the Gnostic, the psychoanalytic and aesthetic visions, the religious syncretism, the mythical and poetic, tragic and expresionst dimensions of his works are the premises of considering Blaga a rewriter of the redemption's canon for his heroes. Firstly, the present paper proposes reading the plays through Goethe's grind - the two souls theory (that of the day and that of the night) corresponding to the maternal and the paternal images, in relation with Blaga's biography. On the other hand, taking in consideration Nietzsche's theory about ancient tragedy, it analyses the rapport between apollonian and dionysian elements, but also the faustization of the heroes. If masculine characters can be related to different faustic steps, the women have both angelic and mephistophelean features - there are correspondents to the Anima, or to the Shadow, in the Jungian archetypes, to the biblical fallen angel or to the ancient Bacchanta. Nona remains a femnine Mephisto or a Sucubous that reshapes the patter of temptention into the erotic seduction while Mira can be seen as a Margareta or even as a Helena, while the church that Manole built on the foundation of her sacrifice can be read in the same grind as Euphorion - the symbol of Beauty and Perfection or of Manole-Faust's new soul. The question if Nona and Mira can represent (or not) the Eternal Feminin and the salvation of heroes is sill valid. However, describing the Priest and Manole as dramatic (not as tragic heroes, although we can talk about the resurrection of Hybris, Hamartia, Catastrophe and a possible Nemesis), in relation with a non-Crestian, Gnostic, Bogumilic or Pantheist God (a Deus absconditus or Deus otiosus), their redemption is a non-canonic one. Although the answer that the author provides if we are talking about a damnation or about a path to redemption, from the religious point of view, the priest's salvation is a Pantheist one, while Manole's redemption can be seen as an aesthetic one. Both parralel with the classic possibilities of saving heroes, alternative models that rewrite the canon of redemption.
\end{abstract}

Keywords: the canon of redemption, plays, Blaga's biography, models, heroes 


\section{Teza}

Pornind de la panoplia literaturii române vechi, se constată o prevalență a modelului religios bizantin, o ortodoxie de fond, care instrumentalizează un imaginar și un paletar tematicomotivic specifice, implicând totodată o valoare didactică, prin dihotomia clară model-antimodel, Bine-Rău, Frumos-Urât. Astfel, tiparele redempțiunii sunt structurate în funcție de grila creștină și de tradiția populară românească. Trecerea de la cultura teocentrică a cronicarilor, în care salvarea însemna mântuirea sufletului, la o cultură antropocentrică (prin secularizarea treptată a subiectelor artei), operează mutaţia de accent înspre alte forme de „salvare”- cea socială, prin eroic/ politic/ elan patriotic, cea personală, prin eros sau autocunoaștere. Modelul canonizat al redempțiunii rămâne însă exemplar, de fond, căci modernitatea nu îl rescrie, ci doar lucrează pro/ contra sau paralel cu acesta (putând menționa, din perioade și estetici diferite, nuvelistica lui Slavici, dramele de conștiință camilpetresciene, literatura realistă interbelică ș.a.).

Teza lucrării de față este că dramaturgia blagiană încearcă rescrierea canonului, deschizându-se, prin jonglarea cu modele culturale europene, înspre o viziune mai largă- gnostică, psihanalitică, estetică, mito-poetică, a redempțiunii.

\section{Premise}

Dramaturgia lui Blaga, statuată de critica literară drept „teatru de idei” (Braga 14-23) universalizează, sub cupola expresionismului, frânturi de mit, legendă și înțelepciune populară, reiterând teatrul-ceremonial, așa cum sugera Doina Modola, sub forme diverse, care lipseau în creația autohtonă: de la misterul antic („Zamolxe”, 1921), la scenariul misterial renascentist (,Tulburarea apelor”, 1923), până la tragedia instauratoare („Meșterul Manole”, 1927) (Modola 14) . Dimensiunea mito-poetică a unora dintre piese, dintre care vom comenta, în cuprinsul lucrării „Meșterul Manole” și „Tulburarea apelor”, se revendică de la intuiția magică a dramaturgului, păstrată din copilăria sub semnul tăcerii, așa cum surprinde în monografia sa exegetul Corin Braga. Astfel, odată cu maturizarea și cu cenzurarea de către o viziune apolinică, rațională, a fondului dionysiac al puberului, în care magicul era calea nemediată către misterul lumii, accesul la magic se face prin mit. „Miticul şi magicul, scrie Blaga fără să distingă pentru moment în mod decisiv între mitologie şi magie, sunt tocmai mijloacele cele mai la îndemână, care îngăduie gândirii saltul mai lesnicios de la «parte» la «Tot»." (Blaga 139) Cristalizând viziunea Ioanei Em. Petrescu, criticul surprinde două etape: „modelul cosmologic adoptiv şi arhetipurile mitice care îl configurează se află la cel de-al doilea nivel, cel al elaborării subconştiente, imediat după primul 
nivel, cel al intuiţiei pure a formei, pe care am identificat-o, în cazul lui Blaga, intuiţiei magice şi avatarurilor acesteia” (Braga 44).

Sub egida magicului, cronotopul mitic (spațiul mioritic în illo tempore), transfigurarea unor narațiuni fondatoare, legitimatoare sau legendare, precum cea a Meșterului Manole, preocuparea pentru figurile dionysiace sau panice creează contextul unui altfel de parcurs al eroului și, implicit, al unei altfel de potențiale salvări (căci nu se face apel la spațiul socio-cultural contemporan, iar viziunea creștină sau pur tradițional-populară este eludată de transferul în planul arhetipal, metafizic).

Sincretismul religios e o altă trăsătură esențială a creației blagiene, de la ortodoxie, la luteranismul protestant, la panteism, la viziunea bogumilică, până la religiile traco-dacice și la cultele animist-htonice, se trec în revistă, în fapt, mai multe modele cosmologice, conform Ioanei Em. Petrescu, etapizate de Corin Braga: cel al „filosofiei orfico-platoniciene”, apoi „Universul magic - cult dionysiac - mitologie tracă”, urmând ,sinteza gnostică” și ,,viziunea ortodoxromânească” (gândiristă) (Braga 47). Imersarea în acest univers infuzat de spiritualităţi diferite (adesea în tensiune) duce la apofatism și mister (Marele Anonim), în conflict cu recunoașterea unui „dumnezeu întrupat”, la consubstanțialitatea cu sacrul, tradusă într-un orgoliu aproape luciferic (,«Fiindcă eu am legătură cu Dumnezeu, chiar eu pot fi Dumnezeu!»“") (Gruia 81), dar și într-un fond tragic asumat. El poate fi explicat și nuanțat atât prin apel la teoria aristotelică, cât și prin teoria autohtonă asupra tragicului, a lui Gabriel Liiceanu.

O ultimă premisă pe care o considerăm importantă în cercetarea noastră este cea a expresionismului blagian, pe care îl postulează critica literară- ,teatrul blagian aparține cu siguranță expresionismului, categorie tipologică ce urmărea redarea lucrurilor sub specie absoluti”(Bârgiu 21). Astfel, personajele nu sunt ancorate într-un cronotop ficțional clar definit, realist/ naturalist, ipostaziate prin etopee și prosopografie, ci capătă o dimensiune universală, de arhetipuri (emfatizându-se natura lor mitologic-legendară și fiind prototipice pentru umanitate, așa cum se vede și din generala absență a numelor- Popa, Omul cu moaştele, Moșneagul, Doctor universalis, Zidarii, etc. sau din alegerea unora simbolice- Mira ș.a.).

\section{Blaga și Goethe}

Copilăria lui Blaga poate fi conjugată prin „călătoria simbolică pe celălalt tărâm”, așa cum el însuși o descrie în opera memorialistică, stând sub semnul basmului adesea povestit de mama sa „Tinerețe fără bătrânețe”; astfel, se ghicește încă din pruncie o formă de segregare a universului în 
lumea materială și „,celălalt tărâm” și chestionarea unei posibile transcenderi, problematică restructurată și în operele dramaturgice. Dualitatea nu este numai a lumilor, ci și a propriei ființe, căci Blaga își privea copilăria prin prisma teoriei goetheene a celor ,două suflete” (Braga 259), cel nocturn și cel diurn, actualizând imagoul patern și pe cel matern. Astfel, dacă mama, Ana Blaga, era exponenta tradiției folclorice și a libertății creatoare, a superstițiilor religioase și a laturii dionysiace, tatăl, Isidor Blaga, devine reprezentatul culturii apolinice, căci, deși preot, este de formație voltairiană și statuează modelul cenzurii raționale. Cele două direcții subînscriu două moduri de existență și, implicit, două forme de „,mântuire”- cea prin suflet/ simţire/ irațional și cea prin spirit/ rațiune/ intelect (Enoia și Nous, în cultele gnostice).

Astfel, această tensiune dintre apolinic și dionysiac pe care copilul o trăiește (mai ales odată cu maturizarea și ,dezvrăjirea”, prin ruperea de cronotopul satului paradisiac- transfigurat în „satul-idee” și racordarea la universul citadin) și dualitatea mijloacelor de ,salvare” sunt transpuse, mutatis mutandis, și în operă. În cazul „Tulburării apelor”, conflicul dintre cele trei forme de credinţă religioasă resemantizează, în fapt, aceeaşi tensiune apolinic-dionysiac- celui dintâi îi corespunde tradiția rutinată, ortodoxă, în timp ce Nona-bacantă tulbură cugetul eroului, prin instrumentalizarea dionysiacului, aparent în luteranism, însă, în esență, prin ispitirea „cărnii”, erotic-orgiastică. Soluția finală, convertirea la panteismul Moșneagului și asumarea continuării acestei misiuni apostolice este tot de sorginte dionysiacă și recuperează, prin modelarea mitului lui Iisus-Pământul, o parte din magia spațiului din pruncia autorului. Totodată, este posibilă o interpretare biografistă, în care tatăl devine modelul Popii din piesă, finalul permițând o salvare prin evaziunea dionysiacă (în acord cu viziunea asupra imagoului matern).

În cazul „Meșterului Manole”, antiteza dintre truda din cei șapte ani în care zidurile s-au surpat continuu și efervescența creației sub auspiciile jertfei, în care Manole devine un daimon, un posedat, recristalizează aceeași mutaţie de la apolinic la dionysiac. Acest cuplu stă la baza nașterii tragediei, conform lui Nietzsche, de la care Blaga recuperează anamnetic elanul vitalist-dionysiac (alături de Bergson, constituind o importantă influență în dinamica gândirii sale). In extenso, putem asocia această tensiune care locuiește operele dramaturgice cu fiorul tragic, căci, în ambele cazuri, climaxul conflictului dintre cele două naturi este jertfa- în cazul Popii, lapidarea Moșneagului, care asumă christic ,păcatul” eroului de a fi dat foc bisericii din sat, urmând a fi ucis de țărani, iar în cazul Meșterului- zidirea Mirei sub semnul jocului tragic.

La catastrofă se ajunge însă prin ceea ce am putea numi „,faustizarea eroului”. Critica discută rolul lui Goethe de model și chiar de catalizator al gândirii și creației blagiene, astfel că 
elementele faustice din piesele alese pot fi ușor explicate. Popa este, la începutul primului tablou, bolnav (așa cum sugerează Patrasia, soția sa): „Erai singur aici - cu uşa deschisă în soare”, Popa răspunzând- „Foamea de soare - e o boală?” și totodată lamentându-se ulterior- „,Sunt aşa de singur. Singur de tot. Ar putea pământul să se prăbuşească, aici nu prinzi de veste”, „E aşa de greu în pustie". El este în ipostaza lui Faust din incipitul operei goetheene, care simte o insufieciență ontologică și o formă a ratării care atince apogeul (lamentația fiind însoțită de tentativa suicidală). Astfel, atât în cazul lui Faust, cât și în cel al Popii, mântuirea creștină implică o formă de stagnare sufletească, de atrofiere morală în dogmă, de „lâncezire” spirituală, antitetică „faptei” pe care o caută. Motivul pactului e resemantizat, de asemenea, sub auspiciile unei trimiteri biblice bivalent semnificate- la îngerul care tulbură apele (Evanghelia după Ioan, 5:1)- „Popa (cu patimă): Nona, de ce-ai venit?/ Nona: Să tulbur apele ca îngerul Domnului./ Sunt rea?/ Minunile de felul meu nu sunt/ Niciodată mai bune." Prima interpretare canonizată este aceea a Nonei ca înger care are menirea de a vindeca lumea de o religie osificată, în care nici Popa nu mai e capabil să creadă. Lucian Bâgiu, contestând această viziune exegetică, sugerează natura luciferică, de înger căzut, a Nonei, care tulbură erotic apele cugetului Popii (,Şi dacă m-ai dorit - de ce? Fiindcă sunt gând sau - sau fiindcă sunt stea păcătoasă de carne vie şi de os neastâmpărat? Fiindcă sunt gând sau fiindcă sunt o păşune caldă pentru visul tău flămând?”).

Se validează, așadar, o posibilă corespondență Nona- Mefisto (Umbră- în accepțiunea arhetipurilor jungiene), căci, venită, nu de la mănăstire, ci din teatrul cetății, unde jucase în misterul despre căderea îngerilor, ea- ,fiica pământului”, este o bacantă menită să ispitească (ca un sucub„Nona, ți-au crescut aripi!”), negând totodată totul- de la ortodoxie (,mâine voi trece desculță prin scrumul unui Dumnezeu ars"- într-un sens aproape nietzscheean al morții lui Dumnezeu), la teologie, în sensul larg (,Popa: Ai învățat și teologia?/ Nona: Numai atât cât să mă plimb râzând printre taine.”), e aducătoarea „cupei celor zece fericiri păcătoase” (tratarea în răspăr a celor nouă fericiri ale Noului Testament) și care instigă la distrugerea bisericii (,,aprinde-ți altarul!”).

Cel care limpezește apele este Moșneagul (arhetipul Bătrânului ințelept), cu natura sa mesianică de a se jertfi pentru a-1 putea valida și întregi ontologic pe Popă- care, conştient de ipostaza sa de ,profet mincinos”, nu mai reușește să fie nici „om”

(„Din potire - aş putea sânge de Dumnezeu să arunc în ţărână - şi totuşi carnea mea tremură. Câteodată iau capul câinelui meu între palme, mă oglindesc în ochii lui - şi simt: i-e milă de mine că-s om. Paşii mei se opresc, mă caut în amintire: de unde vin? Mă caut în zare: unde 
merg? Mă caut în pulberea drumului şi printre hârburi de cerb: cine sunt? Vezi, Nona, acum sunt trist, acum sunt foarte trist. Şi totuşi dac-ar fi iarbă verde aici în jur aş putea să joc desculţ şi nebun în faţa ta. Tu m-ai privi, dar jocul meu ar fi aşa de trist c-ar stârni plângerea.”).

Odată ce bătrânul, încercând să salveze Potirul- ,inima bisericii” din incendiu, asumă păcatul preotului și moare- simetric, în cadrul aceleiași uși în care Popa stătea bolnav, în protagonist se produce iluminarea- îmbătrânit și, ca și cum ar fi trăit un coșmar de veacuri, el asumă apostolic misiunea de a-1 propovădui pe Iisus-Pământul, plecând- ,asta înseamnă că eşti la începutul binelui”, căci „tocmai răsare soarele” (îi spusese Moșneagul). Ducându-se în lume, după sufletul său, ghidat de „,dorul de viață”, „Pe-aici, prin ușa aceasta, ies din mine- om fără nume- viu și sărac.”, Popa se revendică de la tradiția expresionistă a personajului care, printr-o hierofanie, o metanoia, se naște, în final, ca un „om nou” (Faust, de asemenea, dar în viziune neoclasică, ca o regăsire a sinelui profund- din punct de vedere psihanalitic).

Chintesența faustică a personajului stă în tulburarea de ordin spiritual și erotic, tradusă nu doar în relația Nona-Popa, ci și în mai larga tensiune apolinic-dionysiac, ce tronează în piesă: „Dacaș pleca, aș ști poate totul/ Dacă rămân, aș avea poate totul.”. Ca și Mefisto, Nona este ființa care își cunoaște propriul final- „Câteodată visez o biserică albă/ care se scufundă într-o mare de focîncet-încet/ cu viața mea”, fiind arsă, în tradiția medievală a epurării răului din comunitate, reprezentat de vrăjitoare, prin focul purificator. Înainte de moartea ei simbolică însă (ca o întoarcere la elementul care a generat-o), Nona, ca și Mefisto, care trudește pentru câștigarea sufletului lui Faust, „obosește” („Popa: Ești ostenită de tine?/ Nona: Atâtea zile și nopți/ mi-am sfâșiat ființa râzând./ Popa: Și-acum ești frântă de tinerețea ta.").

În cazul Meșterului Manole, problematica faustică se mută în planul creației, căci, spre deosebire de personajul baladesc, cel blagian nu mai e stăpânit de patimă (a creaţiei) la modul absolut, încă din incipit ci, mai problematizant și profund umanizat, este scindat între două doruri capitale- cel pentru viață și iubire și cel pentru creație.

Dacă Nona era un Daimon exterior, o patimă care îmbolnăvea, ca un element alogen care irumpe în sufletul Popii, Meșterul este el însuși Daimonul (în sens goetheean, nu creștin, în care natura genial-umană este în perpetuă competiţie cu Divinitatea, în planul creației și devenirii ei ca un demiurgos). Critica dezbate problematica liberului arbitru și a fatalității în cazul meșterului, părerile fiind variate: Eugen Todoran (Todoran 95) pledează pentru asumarea conștiinței artistice și a libertăţii, până la jertfă, în timp ce Ion Bălu (Bălu 201)discută tragismul și fatalitatea- esențiale în construcția eroului. Personaj dual („Lăuntric, un demon strigă: «Clădeşte!». Pământul se- 
mpotriveşte, şi-mi strigă: «Jertfeşte!»”), căruia Lucian Bâgiu îi recunoaşte atât valenţele prometeice, cât și pe cele sisifice (Bârgiu 130), el ridică problematica celor două zădărnicii, al căror factor generator este cunoașterea, așa cum explică Gh. Cimpoec: „mintea iscoditoare, înfrântă în demersul ei raţional, e pusă în faţa unor obstacole de netrecut - nu înainte însă de a oferi spectacolul măreț şi dramatic al omului însetat de adevăr" (Ciompec 122), căci, conform lui Blaga, limita este impusă tocmai pentru ca omul ,să nu poată revela, în chip pozitiv şi absolut, niciun mister” (Blaga 37).

Astfel, Bâgiu spune că ,pe parcursul evoluţiei conflictului dramatic, Manole va înţelege că nu transcendenţei va trebui să îi sacrifice sufletul, ci sie însuşi. Pentru a deveni creator artist, va trebui să renunţe la postura de om, anume să confere alte valenţe sufletului său. Iar sufletul său este Mira.” (Bârgiu 131). Femeia, al cărei nume, etimologic, vine din latinescul „mirror”, ,a se mira”, întrupează „,dorul de viață” al meșterului („Tu început, tu sfârşit, tu totul”; „Mira, tu eşti lumina omului!”, „Viaţă fără pereche eşti”), capacitatea lui de a-și păstra inocența în fața misterului nerevelat. Odată cu jertfa, echivalentă inițierii lui Manole, demistificării și cunoașterii, Manole devine un Adam căzut, incapabil să se mai mire- ca raport la absolut, și, implicit, să trăiască. Își pierde capacitatea profetic-mesianică instaurată în faţa meșterilor săi, odată ce i-a chemat și i-a adunat din lume, ca pe apostoli, pentru a-i îmbolnăvi de dorul imaginii bisericii din ei. Jertfa- ,nu numai acţiune tranzitivă (a sacrifica ceva), ci şi (obligatoriu) acţiune reflexivă (jertfa de sine)” (Ciompec 132), este pierdere a sinelui, prin jocul nebuniei-creaţie (,A mea a fost patima, eu am fost al patimei, eu am fost”, „Uită-te la mine: mai sunt eu cel ce am fost? Manole nu mai este. Priveşte mâinile astea sângerate din senin; sunt ale mele? Manole a plecat. Manole nu mai este”). Meșterul are o pronunțată valență orfică- „Lăcaşul creşte nebun. Va fi un cântec de iubire împletit cu un cântec de moarte".

Dacă pe Nona am circumscris-o deja unei imagini luciferic-ispititoare, de Umbră jungiană, se cere chestionată natura Mirei, în raport cu Manole-Faust, pentru a stabili potențialitatea ei de salvator. Ea este o Margareta sacrificată pentru cunoaștere, înţeleasă aici drept creație, creionată exegetic atât în lumina apolinică a animei, a „femeii-copil”, ,candoarea însăși” (Gană 355-364), cât și în cea dionysiacă a unui altfel de daimon, (Mihăilescu 98) care joacă pe spatele lui Găman, într-o ,incantație bachanală”, prefigurându-și ipostaza de femeie-biserică. Dacă Margareta își ucide pruncul, pierzându-și mințile, Mira anticipează singura ei naștere, de ordin simbolic/estetic - biserica-odor. Ea însăși surprinde o bivalență neobișnuită- pe de-o parte este naivă în raport cu jocul tragic al zidirii și morții, iar pe de cealaltă, este vocea adevărului: „Parcă 
Dumnezeu s-a întors acum cu spatele către noi şi stăm în umbra lui”, ,Manole, ai mai văzut minuni înălţate pe moarte?”. Totodată, raportându-ne la partea a II-a a poemului dramatic goetheean, considerăm că se poate creiona și o paralelă între Mira și Elena- în sensul nuntirii și rodirii pur estetice- Euphorion devenind aici biserica- ideal artistic.

Titus Bărbulescu este evocat de Bâgiu, vorbind despre tema femeii mântuitoare în opera lui Blaga. Totodată, în sprijinul acestei ipostaze a Mirei vine și viziunea hermeneutică a lui Dan C. Mihăilescu: „Dincolo, însă, de faptul că ea, prin jertfire îl «absolvă» pe Manole de pământ, de efemer, Mira este o continuă forţă esenţială pentru Manole, noima condiţiei sale de a fi şi de a MAI rămâne al pământului. Pentru că, dacă Zidirea este rostul spiritual al lui Manole, Mira este rostul însuşi al fiinţei lui”. (100)

Întrebarea dacă Mira poate fi însă asociată ,,eternului feminin” care îl salvează de la eterna damnare pe Faust rămâne deschisă, dependentă de răspunsul pe care îl putem da la problematica redempțiunii în cazul lui Manole.

Amplificarea problemei iniţiale a raportului dintre libertate și fatalitate, precum și a tragismului eroului e generată de ipostazierea lui Dumnezeu ca un Deus absconditus și ca un Deus otiosus. Nu doar că nu există Revelația, însă Manole, cel care înfăptuiește jertfa aparent pentru Divinitate, nu mai înțelege mecanica internă a propriului raționament și raportul cu transcendentul (lamentația lui stă sub semnul pierderii a tot ceea ce a avut- a jertfei totale, care, brusc, devine nefondată). După transcenderea acestei etape de lamentație elegiacă, în cadrul căreia, în opinia noastră, se consacră ca personaj tragic, în spiritul definiției oferite de Gabriel Liiceanu (Tragicul, care este întotdeauna „la hotar”, apare prin ,întâlnirea unei ființe conștiente finite cu propria sa finitudine percepută ca limită”, prin ,tentarea limitei absolute”) (Liiceanu 53), Manole își recunoaște limita. Monologul lui final se cristalizează într-o mutaţie axiologică fundamentală-

„,.. vreau în socoteala mea să se pună sugrumarea vieţii, dar lăcaşul nu. Acesta, Dumnezeu singur şi 1-a ridicat, printr-o minune, pe care doar El o înţelege. Eu am fost numai o netrebnică unealtă, o scândură în schelele pe care le dărâmi când clădirea e gata, şi folosul vremelnic nu le mai cere. Aşa suntem toţi, unelte şi scânduri în schele; unii-şi dau seama mai curând, alţii mai târziu".

Păcatul, înțeles și asumat în sesul aristotelic al hamartiei- greșeala tragică, este recunoscut simultan cu fatalitatea, înaintea sinuciderii. 


\section{Redempțiunea și rescrierea canonului- Concluzii}

Trebuie să reiterăm ideea de fior tragic ce traversează ambele piese discutate- atât Popa, cât și Manole putând fi caracterizați de patima care îi ia în posesie, de hybris (o hipertrofiere a orgoliului, înțeles în sens daimonic, vina tragică). În cazul amândurora există o formă a Destinului care pare să îi subjuge (Moșneagul știe de dianinte că trebuie să se sacrifice pentru Popă, ,un ales”, în acest context, în timp ce Meșterul stă sub auspiciile sorții care nu îl lasă să înalțe biserica și o aduce pe Mira în mijlocul lor în locul oricărei alte soții). Având în vedere însă raportarea la jertfă, precum și construcția personajelor conflictul interior al eroilor, trebuie subliniat că ei sunt, mai degrabă, personaje dramatice decât tragice (Moșneagul- unidimensional și cu valențe de țap ispășitor, fiind mai degrabă tragic, decât Popa sau Manole). Ca personaje dramatice, finalul lor este chestionabil, nu mai stă sub semnul Nemesisului (pedeapsa pe care zeii o dau muritorilor care se răzvrătesc împotriva ordinii transcendentale impuse, încercând să-și surclaseze condiția mundană și să-şi schimbe destinul înscris de Moire). Conflictul și profunzimea psihologică a personajelor permit libertatea absolută a dramaturgului, în sensul salvării sau damnării acestora.

Astfel, pentru a explica opțiunea auctorială pentru finalul „Tulburării apelor” trebuie să revenim la paralelismul cu „Faust”. Atât în elanul de Sturmer, cât și în echilibrul neoclasic, opera capitală a lui Goethe propune, încă din „Prologul în cer”, o viziune gnostică mai degrabă decât una creștină, asupra lui Dumnezeu și a Diavolului (,parteneri”, demiurgi a două împăăății diferite), astfel că mântuirea unui Faust maturizat și renăscut nu poate respecta ad literam canonul creștin, ci se constituie într-o nuanțare a acesteia, într-un final deschis. În aceeași direcție, redempțiunea, în cazul protagonistului blagian, capătă valențe metafizic-gnostice și simbolice, aşa că, prin mutaţia în ordinea ființei provocată de jertfă, Popa nu este damnat, deși se leapădă de ortodoxie, ci este salvat prin conecatarea la Dumnezeul-Pământ sau la Anima Mundi (nu la Nous- Intelect). Fiind „opera aperta”, piesa nu emite un model de salvare- nu știm dacă Popa se va mai întoarce vreodată, ce se va întâmpla cu el sau cu Radu și Patrasia, ci se redeschide înspre potențialitățile vieții, înțelese în cheie dionysiac-vitalistă.

În cazul lui Manole, finalul permite multiple interpretări. De exemplu, în direcția exegezei lui Dan C. Mihăilescu, mai sus-citată, în care, prin împlinirea menirii creatoare (așadar, prin zidirea Mirei, ca jertfă de sine), meșterul se mântuiește (ca un Faust)- prin „eternul feminin”, adică prin întoarcerea în Dumnezeu (ca o „scândură”, o „unealtă”, care și-a îndeplinit scopul mundan). Antitetic, ea poate fi citită în grila damnării creștine (a celui care a râvnit ca, prin jertfa de sânge și prin hiperbolizarea orgoliului luciferic, să se ridice deasupra lui Dumnezeu în creație). Considerăm 
însă că salvarea Meșterului Manole nu ține de contextul mitico-religios, de acesată dată, căci pendularea între pietate și răzvrătire în fața Divinității creionează o ambiguitate insurmontabilă. Nu se poate răspunde clar la întrebarea ridicată de exegeți- ,,este fatalitate sau alegere?”, astfel că sinuciderea poate fi văzută ca o încheiere a actului creator, sau ca o evaziune în neant, căci viața se desacralizează și își pierde scopul- adică o fie ca o opțiune estetică, fie ca una existențială. Esenţial ni se pare însă că Meșterul devine, în final, simultan, judecător, victimă și călău, mutând întregul conflict al dramei în spațiul interiorităţii sale abisale și substituindu-se Divinităţii. De asemenea, în opinia noastră, redempțiunea este una de ordin estetic- „Doamne, pentru ce vină neştiută am fost pedepsit cu dorul de a zămisli frumuseţe?”, căci, deasupra dorului de viață și a dorului de absolutca o sinteză a celor două contrarii se ridică „,dorul de a zămisli frumusețe”, în cheia esteticului, ca principiu absolut.

In nuce, panoramând câteva trăsături pe care le considerăm simptomatice în creaţia dramaturgică a lui Lucian Blaga și raportându-ne la canonul literar românesc de până la el, dar și la modelele universale care îi modelează gândirea creatoare, am încercat să problematizăm noua poetică a redempțiunii, prin analiza celor două piese mito-poetice- „Tulburarea apelor” și „Meșterul Manole”.

\section{Bibliografie:}

Bălu, Ion.Opera lui Lucian Blaga. Bucureşti: Albatros, 1997.

Bâgiu, Lucian. Lucian Blaga şi teatrul. Eseu despre absolutul estetic. Iași: Tipo Moldova, 2014.

Blaga, Lucian. Opera dramatică, volumul I. Sibiu: „Dacia Traiană” S. A., 1942.

Blaga, Lucian. Opera dramatică, volumul II. Sibiu: „Dacia Traiană” S. A., 1942.

Braga Corin,Lucian Blaga. Geneza lumilor imaginare. Bucureşti: Tracus Arte, 2013.

Ciompec, Gh.. Motivul creaţiei în literatura română. Bucureşti: Minerva, 1979.

Gană, George. Opera literară a lui Lucian Blaga. Bucureşti: Minerva, 1976.

Liiceanu, Gabriel. Tragicul. O fenomenologie a limitei și a depăşirii. București: Humanitas, 2005. Mihăilescu, Dan C.. Dramaturgia lui Lucian Blaga. București: Dacia, 1984. Print.

Modola, Doina. Lucian Blaga și teatrul. Insurgentul. Memorii. Publicistică. Eseuri. București:Anima, 1999.

Todoran, Eugen. Dramaturgia lui Lucian Blaga. În vol. ***, Lucian Blaga. Studiu, antologie, tabel cronologic şi bibliografie de Emil Vasilescu, Bucureşti: Eminescu, 1981. 